REVIEW

\title{
Chronic obstructive pulmonary disease: the clinical management of an acute exacerbation
}

\author{
J R Hurst, J A Wedzicha
}

Postgrad Med J 2004;80:497-505. doi: 10.1136/pgmi.2004.019182

Exacerbations of chronic obstructive pulmonary disease impose a considerable burden of morbidity, mortality, and health care cost. Management guidelines outlining best practice, based largely on consensus expert opinion, were produced by a number of organisations during the last decade. Current interest in the field is high. This has resulted in the publication of many further studies which have extended our understanding of the pathology involved and provided, for the first time, an evidence base for many of the therapeutic options. In this review we aim to bring the non-specialist reader up to date with current management principles and the evidence underlying such interventions.

See end of article for authors' affiliations

.....................

Correspondence to: Professor J A Wedzicha, Academic Unit of

Respiratory Medicine, Dominion House, St Bartholomew's Hospital, London ECIA 7BE, UK; J.A.Wedzicha@qmul.ac. uk

Submitted 13 January 2004 Accepted

23 February 2004
$\mathrm{T}$ he case history described below will be familiar to many physicians working in both primary and secondary care. This review will consider current concepts in the clinical management of an exacerbation of chronic obstructive pulmonary disease (COPD) and explore the evidence basis underlying such decisions. We conclude by posing some questions relating to the case history (see next page).

\section{WHAT IS AN EXACERBATION?}

The recent World Health Organisation document entitled Global Initiative for Chronic Obstructive Lung Disease (GOLD) defines COPD in terms of airflow limitation that is progressive, not fully reversible, and associated with an abnormal inflammatory response of the lung to noxious stimuli. ${ }^{1}$ The relentless decline in lung function is punctuated by intermittent episodes characterised by deterioration of symptoms termed "exacerbations". Exacerbations become more frequent and severe as the severity of the underlying disease increases. ${ }^{2}{ }^{3}$ In a study of patients with moderately severe disease, the median exacerbation frequency was 2.7 per year. $^{4}$

To exacerbate, from the Latin "exacerbare" and meaning to make harsh, is generally used to imply the process of making something bad, worse. In practical terms exacerbation is a clinical diagnosis manifest by a sustained worsening of symptoms from the stable state that is acute in onset, and beyond the patient's usual day to day variation. These symptoms typically include increased breathlessness, sputum volume and sputum purulence, perhaps accompanied by increased cough, wheeze, chest tightness, features of a cold, oedema, fatigue, or confusion. There is, however, considerable debate about the precise definition of exacerbation. While differences between definitions may seem subtle, they are of great importance in the interpretation of clinical studies. Some definitions, including a recent attempt to obtain consensus, ${ }^{5}$ include a health care utilisation component such that the change in symptoms must necessitate a change in treatment. However, including health care utilisation adds a number of diverse and unpredictable variables to the underlying pathophysiological mechanisms. These include local health care resources, the patient's perception of the severity of the symptoms, and the economic and social situation of the patient. Furthermore, studies using a purely symptom based definition have illustrated that up to $50 \%$ of exacerbations go unreported to health care professionals and that these may be just as severe as reported events. ${ }^{4}$

Constructing a definition is complex because exacerbations are extremely heterogeneous. A broad description is required to encompass the range of events from a worsening of symptoms in a patient with mild COPD to the life threatening episodes of respiratory failure experienced by patients with more severe underlying disease. A deterioration in symptoms beyond usual day to day variation is the common factor and it is that which is relevant to daily clinical practice.

\section{CAUSES OF EXACERBATIONS}

Most exacerbations are caused by tracheobronchial infection or pollutants and the common aetiological agents are listed in box 1. Depending on the methods of detection employed, individual percentages vary and in a proportion of exacerbations the cause remains obscure.

Respiratory viruses account for around 30\% of exacerbations and the single most important viral pathogen is human rhinovirus. ${ }^{6}$ Viral circulation, and therefore exacerbation incidence, is more common during the winter months. ${ }^{7}$ In addition, cold weather causes a reduction in lung function which may interact with pollutants and viruses to further increase exacerbation frequency. ${ }^{8}$ Viral exacerbations are associated with greater symptoms ${ }^{9}$ and a longer recovery period ${ }^{6}$ and are therefore more severe.

\footnotetext{
Abbreviations: COPD, chronic obstructive pulmonary disease; ECG, electrocardiogram; GOLD, Global Initiative for Chronic Obstructive Lung Disease; NICE, National Institute for Clinical Excellence; NIV, noninvasive ventilation; $\mathrm{PaO}_{2}$, partial pressure of arterial oxygen; $\mathrm{PaCO}_{2}$, partial pressure of arterial carbon dioxide; $V / Q$, ventilation-perfusion
} 


\section{Case history}

A 72 year old woman was referred as an emergency to her local hospital. After developing a cold three days earlier she had become progressively more breathless and had a cough productive of white sputum. She stopped smoking three years before, having previously smoked 10 cigarettes per day from the age of 16. Over the last few years she had noticed a "smokers' cough" and increasing exertional dyspnoea for which her primary care physician had prescribed an inhaled bronchodilator. She described a tendency for colds to "go down to her chest". Clinical examination reveals a tachycardia, tachypnoea, and impaired chest expansion. There is bilateral reduced air entry and expiratory polyphonic wheeze. Her chest radiograph demonstrated hyperexpansion but no other focal abnormality, and the electrocardiogram confirmed sinus tachycardia. Her oxygen saturations on arrival, breathing room air, were $87 \%$ and she was started on oxygen $(4 \mathrm{l} / \mathrm{min}$ ) via nasal cannulae. Arterial blood gas tensions subsequently revealed $\mathrm{pH} 7.33$, partial pressure of arterial oxygen $\left(\mathrm{PaO}_{2}\right) 8.1 \mathrm{kPa}$, and partial pressure of arterial carbon dioxide $\left(\mathrm{PaCO}_{2}\right) 9.1 \mathrm{kPa}$. The attending doctor diagnosed an exacerbation of COPD and started therapy with nebulised salbutamol, oral prednisolone, and amoxicillin. Is this initial management correct and what is the evidence basis for such interventions? What additional therapies may be employed and does the patient require admission to hospital?

The three most common bacterial isolates are Haemophilus influenzae, Streptococcus pneumoniae, and Moraxella catarrhalis. The role of bacteria in causing exacerbations is controversial because the same organisms may be isolated in up to 30\% of patients at clinical stability. This phenomenon, termed "bacterial colonisation", is associated with continued cigarette smoking and increasing severity of underlying disease. ${ }^{10}$ Much of the evidence that bacteria are an important cause of exacerbations is therefore extrapolated from the benefit seen in trials of antibiotics. The presence of colonisation is not benign and may itself modulate exacerbation frequency ${ }^{11}$ and contribute to a more rapid decline in lung function. ${ }^{12} \mathrm{~A}$ recent study has suggested that exacerbation may be the result of acquiring new strains of bacteria. ${ }^{13}$ Sputum purulence is a reliable indicator of the presence of bacteria. ${ }^{14}$

A number of studies have examined the role of pollutants at exacerbation of COPD and it has been shown that increasing air pollution correlates with higher hospital admission rates. ${ }^{15}$ Most data are available for ozone, but particulates and oxides of sulphur and nitrogen have also been implicated.

\section{IMPORTANCE OF EXACERBATIONS}

Much of the morbidity and mortality in COPD may be attributed to exacerbations. Admissions to hospital due to exacerbations are increasing in frequency ${ }^{16}$ and account for $10 \%$ of all acute medical admissions in the UK. ${ }^{17}$ In-hospital mortality is approximately $10 \%^{18}$ and associated with the severity of exacerbation; especially refractory hypoxia, increasing age, malnutrition, and the presence of comorbidities. In addition to significant mortality, patients experiencing frequent exacerbations are known to have a poorer quality of life, ${ }^{4}$ and exacerbation frequency has recently been linked with an accelerated decline in lung function. ${ }^{19} 20$ Finally, exacerbations and particularly hospitalisations in patients with more severe underlying disease account for
Box 1: Causes of exacerbations in COPD (bold type indicates the most commonly identified agents)

Viruses:

- Rhinovirus.

- Coronavirus.

- Influenza.

- Parainfluenza.

- Adenovirus.

- Respiratory syncytial virus.

Bacteria:

- Haemophilus influenzae.

- Streptococcus pneumoniae.

- Moraxella catarrhalis.

- Pseudomonas aeruginosa.

Atypical organisms:

- Chlamydia pneumoniae.

- Mycoplasma pneumoniae.

Pollutants:

- Oxone.

- Particulates.

- Sulphur dioxide.

- Nitrogen dioxide.

around $70 \%$ of the direct medical costs of COPD. ${ }^{21}$ Exacerbations of COPD are therefore an important cause of morbidity, mortality, and health care cost.

\section{ASSESSMENT}

In the section above we have described exacerbation of COPD as a clinical diagnosis: there is no confirmatory diagnostic test. Evaluation of the patient with a possible exacerbation therefore focuses on assessing the severity of the episode and excluding other causes for deterioration in symptoms. A full history and clinical examination are essential. It is particularly important to assess the work of breathing, considering respiratory rate and use of accessory muscles, and the presence of signs suggesting hypercapnic respiratory failure including cyanosis, flapping tremor, confusion, and the presence of peripheral oedema. Important differential diagnoses are listed in box 2 and most may be excluded in the hospital setting with a clinical history, examination, and the addition of simple investigations such as the electrocardiogram (ECG) and chest radiograph. Most published guidelines recommend a full blood count and electrolyte assay, ECG, chest radiograph, and arterial blood gas analysis. ${ }^{122-26}$ Theophylline levels are suggested for patients taking these drugs, and sputum culture and sensitivity testing is useful for those with sputum purulence. Assessment of lung function by spirometry or peak flow is not generally helpful: changes at exacerbation are small, absolute values may be misleading, and the tests are difficult to perform in patients who are acutely unwell.

Assessment of severity is useful in guiding decisions on initial treatment strategy and whether a patient requires hospital admission. A minority need hospital care and early supported discharge is a further option considered in more detail later in this review. Important factors to consider regarding the necessity for admission to hospital include the 
Box 2: Differential diagnosis for deterioration of symptoms in a patient with stable COPD

Respiratory:

- Acute exacerbation.

- Pneumonia.

- Pneumothorax.

- Pleural effusion.

- Lung carcinoma.

- Pulmonary embolus.

Cardiac:

- Cardiac failure.

- Cardiac arrhythmia.

Other:

- Rib fracture.

- Upper airway obstruction.

need for therapy not available at home, comorbidities, and the lack of appropriate social support. There is no widely accepted scoring system to assess severity. $\mathrm{pH}$, rather than $\mathrm{PaCO}_{2}$, is an important marker since this reflects acute changes in alveolar ventilation. ${ }^{27}$ The GOLD document suggests that a $\mathrm{pH}<7.30$ represents a life threatening exacerbation. ${ }^{1}$ The published guidelines, ${ }^{122-26}$ all provide broadly similar recommendations on the necessity of hospital admission, and factors which should be considered are listed in box 3. These factors are also those which a primary care physician will wish to address in deciding whether or not a patient reviewed in the community requires hospital assessment.

\section{TREATMENT}

In the following section we outline the different therapies available at exacerbation of COPD and discuss the underlying rationale and evidence basis. Treatment is employed either to target the underlying pathology, or to support respiratory function while disease modifying therapies are able to act. Many national and international guidelines on the management of both stable COPD and exacerbations were published during the last decade, primarily based on consensus expert opinion. ${ }^{22-25}$ The World Health Organisation GOLD document is more recent and was the first to provide explicitly evidence

Box 3: Factors suggesting hospital assessment or admission in exacerbation of COPD

- Marked increase in intensity of symptoms.

- Severe background COPD (GOLD stage IV).

- Onset of new physical signs (for example, cyanosis or oedema).

- Altered mental status.

- Failure to respond to initial medical management.

- Requirement for therapy not available at home.

- Significant comorbidities (for example, cardiac failure).

- Diagnostic uncertainty.

- Older age.

- Insufficient home support. based recommendations. ${ }^{1}$ It was last updated during 2003 and is available online at www.goldcopd.com. In the UK, further guidelines have recently been published by the National Institute for Clinical Excellence (NICE). ${ }^{26}$

\section{Bronchodilators}

Inhaled bronchodilator drugs are the mainstay of treatment in stable COPD. Although the airflow obstruction in COPD is, by definition, largely irreversible these drugs may produce considerable symptomatic benefit through mechanisms including an effect on dynamic hyperinflation. ${ }^{28}$ At exacerbation there may be additional bronchoconstriction, due to complex inflammatory-neural interactions, that results in further hyperinflation. It is therefore logical to increase both the dose and frequency of administration of bronchodilator agents. Current guidelines give preference to the short acting $\beta_{2}$-agonists such as salbutamol. The drug has a rapid onset of action, reaches peak activity at between 10 and 30 minutes, and remains effective for between four and six hours. This is a more rapid onset but shorter total duration than the anticholinergic bronchodilator ipratropium. Although in stable disease there is evidence that anticholinergics achieve superior bronchodilation, ${ }^{29}$ with the higher doses used at exacerbation there are no differences seen and, furthermore, a meta-analysis has shown no evidence of a synergistic effect. ${ }^{30}$ Despite this, guidelines recommend the addition of an anticholinergic agent when therapy with a $\beta_{2}$-agonist alone is insufficient to achieve improvement. A meta-analysis has shown no benefit of nebulised therapy over inhalation via a spacer device, ${ }^{31}$ but patients acutely short of breath may not be able to achieve an adequate inhalation technique with inhalers. Nebulised therapy is also more expensive. ${ }^{32}$ There is currently no evidence for a role of long acting bronchodilators in treating exacerbations. Although there are data supporting the use of intravenous salbutamol in acute severe asthma, no such evidence exists for its use at exacerbation of COPD. In addition, troublesome side effects (most commonly tremor and palpitation) are more frequently seen than with inhaled delivery due to the increased stimulation of extrapulmonary $\beta$-adrenoreceptors. Similarly, continuous nebulisation of salbutamol is not recommended..$^{33}$ Clinically important side effects from ipratropium are rarely encountered.

\section{Corticosteroids}

Exacerbations are associated with increased airway inflammation $^{34}{ }^{35}$ which therefore provides a rationale for the use of anti-inflammatory corticosteroid therapy. Systemic steroids form the cornerstone of treatment in all but the mildest of exacerbations which have responded to an increase in bronchodilator medication alone. Two recent systematic reviews summarising a number of randomised trials have shown the benefit of steroids in providing a greater improvement in early forced expiratory volume in one second recovery. ${ }^{36} 37$ However, improvements in oxygenation and duration of hospitalisation were more variable and there is no evidence to support a mortality benefit. There is, however, a suggestion that the use of steroids may prolong the time to a subsequent exacerbation. ${ }^{38}{ }^{39}$ The GOLD guidelines recommend a dose of $30-40 \mathrm{mg}$ prednisolone continued for between 10 and 14 days. ${ }^{1}$ Tapering courses are not of additional benefit in asthma but the relevant studies in COPD have not been performed. ${ }^{40}$ Prolonging treatment is not advantageous and increases the incidence of side effects, especially hyperglycaemia. ${ }^{41}$ The NICE guidelines recommend that patients receiving multiple courses of oral steroids should receive prophylaxis against osteoporosis. ${ }^{26}$ Many physicians, in the acute setting, will give a first dose of steroid intravenously and one of the trials included in the reviews outlined above did employ and show benefit from intravenous methylprednisolone. ${ }^{42}$ Nebulised budesonide 
causes similar improvements in lung function to oral treatment but is more expensive. ${ }^{43}$ There is no role for initiating inhaled corticosteroids at the time of exacerbation, but patients already prescribed these drugs would normally continue in their use, and inhaled steroids have an important role in the prevention of exacerbation that is discussed later in this review.

\section{Antibiotics}

Since many exacerbations are believed to be bacterial in origin the rationale for antibiotic treatment is intuitive. The seminal work by Anthonisen et al only showed evidence of benefit from antibiotics in exacerbations characterised by at least two of the following three symptoms: increased dyspnoea, sputum purulence, or sputum volume. ${ }^{44}$ That is, there had to be a change in the character of the sputum for antibiotics to be beneficial. Sputum purulence is a reliable indicator of the presence of bacteria. ${ }^{14}$ Bacteria are a more common cause of exacerbation in those with more severe underlying disease and a community study of exacerbations in milder patients demonstrated no acceleration of recovery or reduction of relapse with antibiotics. ${ }^{45}$ Overall, a metaanalysis by Saint et al found a small but significant benefit in favour of antibiotics at exacerbation of COPD. ${ }^{46}$ The NICE guidelines have recommended that patients without sputum purulence do not require antibiotics since such exacerbations are unlikely to be bacterial in origin. ${ }^{26}$ Many different antibiotics have been employed but coverage of $H$ influenzae, $S$ pneumoniae, and $M$ catarrhalis is required. Local susceptibility patterns and antibiotic policies must also be considered. Parenteral antibiotics are rarely necessary. Initial empiric therapy would usually employ an oral aminopenicillin, macrolide, or tetracycline agent. There are few comparative trials $^{47}{ }^{48}$ but the data suggest less treatment failure with newer drugs such as macrolides and quinolones, which must be balanced against the higher costs and implications for microbial resistance. Increasing problems with penicillin resistance among pneumococcal isolates, and $\beta$-lactamase producing $H$ influenzae have already been noted. ${ }^{49}$ It is possible that macrolides have a greater impact on mortality, ${ }^{50}$ perhaps because of the additional anti-inflammatory properties these drugs possess.

\section{Methylxanthines}

Methylxanthine drugs act via a variety of mechanisms including increasing respiratory drive, improving respiratory muscle function, enhancing mucociliary clearance, and as bronchodilators. They may also possess anti-inflammatory and immunomodulatory functions. At exacerbation, the drug most commonly used is intravenous aminophylline. A recent meta-analysis considering three randomised trials and one abstract found no benefit in improvement of pulmonary function or symptoms. ${ }^{51}$ In addition to this lack of objective benefit, the drugs have problems with a narrow therapeutic interval that causes frequent gastrointestinal side effects and less common but more serious toxicities such as cardiac arrhythmia. Serum monitoring is therefore required. There are important interactions with other drugs including the quinolone antibiotics. Routine use is not recommended. Patients already taking oral preparations of methylxanthines for stable disease would normally continue on such treatments at the time of exacerbation.

\section{Respiratory stimulants}

The use of centrally acting respiratory stimulants, most commonly given as intravenous doxapram, has declined with the introduction of non-invasive ventilation (NIV) which has clear superiority in the management of hypercapnic respiratory failure. ${ }^{52}$ A recent Cochrane review concluded that while being the most effective respiratory stimulant, doxapram was only able to achieve minor short term improvements in blood gas tensions. ${ }^{53}$ In addition, any beneficial effects only last between 24 and 48 hours and use is limited by the common side effect of agitation. There may still be a role for the use of doxapram where NIV is considered inappropriate, as a holding measure before the introduction of NIV, or (with specialist advice) as an adjunct to NIV.

\section{Oxygen}

Hypoxia at exacerbation of COPD is primarily the consequence of ventilation-perfusion (V/Q) imbalance and may be life threatening, for example through cardiac arrhythmia. ${ }^{54}$ Oxygen should therefore be used to correct hypoxia in respiratory failure. This should be administered in a controlled manner, to prevent the hypercapnia which will occur in a minority of patients. ${ }^{55}$ The usual explanation for worsening hypercapnia arises from the finding that in patients with chronic hypercapnia the main stimulus to respiration is hypoxic drive. Overcorrecting the $\mathrm{PaO}_{2}$ therefore results in increasing carbon dioxide retention and acidaemia. ${ }^{56}$ Studies have shown that there is little risk of carbon dioxide retention and acidaemia when oxygen is delivered to achieve maximal oxygen saturations of between $90 \%$ and $92 \%{ }^{57}$ Failure to correct hypoxaemia to $90 \%$ with the fraction of inspired oxygen $>40 \%$ suggests the presence of additional pathology, for example pulmonary embolus, pneumonia, or atelectasis. Around $20 \%$ of patients with an exacerbation present to hospital with acidaemia. ${ }^{55}$ In these patients, $\mathrm{PaO}_{2}$ is inversely proportional to $\mathrm{pH}$, in other words the greater the overcorrection of $\mathrm{PaO}_{2}$, the more severe the resulting acidaemia. Arterial blood gas analysis should be performed in all patients with oxygen saturations less than $90 \%$ and repeated 30 minutes after instituting or changing the amount of oxygen therapy. Current British Thoracic Society guidelines recommend that $\mathrm{PaO}_{2}$ be maintained at $>7.5 \mathrm{kPa}$ when $\mathrm{pH}$ is satisfactory, or $>6.6 \mathrm{kPa}$ where there is a fall in $\mathrm{pH}^{25}$ Achieving adequate oxygenation only at the expense of deteriorating $\mathrm{pH}$ or rising $\mathrm{PaCO}_{2}$ suggests the need for noninvasive ventilation. Venturi masks provide a more reliable oxygen concentration and are less likely to be dislodged than nasal prongs, but are not as well tolerated. ${ }^{58}{ }^{59}$ Ear lobe gases may not accurately reflect the $\mathrm{PaO}_{2}$ and are not necessarily less painful. ${ }^{60}$ When prescribing nebulised therapy it is good practice to define the driving gas. Hypercapnic or acidaemic patients should receive nebulisers driven on compressed air, receiving any supplemental oxygen separately via nasal cannulae. Omission of supplemental oxygen during nebulisation risks the development of hypoxaemia.

\section{Non-invasive ventilation}

At an exacerbation of COPD, additional bronchoconstriction may result in increased dynamic hyperinflation that can increase the work of breathing. Furthermore, there is considerable evidence that COPD is a systemic disorder, one

Table 1 Relative indications and contraindications for NIV at exacerbation of COPD

\begin{tabular}{ll}
\hline Indications & Contraindications \\
\hline $\begin{array}{l}\text { Exacerbation with respiratory } \\
\text { acidaemia } \mathrm{PaCO}_{2}>6 \mathrm{kPa} \text { and } \\
\mathrm{pH}<7.35 \text { but }>7.25\end{array}$ & Inability to protect airway \\
Respiratory rate & \\
$>24$ breaths $/ \mathrm{min}$ & Life threatening hypoxaemia \\
& $\begin{array}{l}\text { Haemodynamic instability } \\
\text { Impaired consciousness or agitation } \\
\end{array}$ \\
& $\begin{array}{l}\text { Undrained pneumothorax } \\
\text { Inability to clear respiratory secretions }\end{array}$ \\
\hline
\end{tabular}


manifestation of which is skeletal muscle dysfunction. In patients with severe underlying disease and poor respiratory reserve an exacerbation may therefore precipitate respiratory failure. Respiratory failure is defined as $\mathrm{PaO}_{2}<8 \mathrm{kPa}$ or $\mathrm{PaCO}_{2}$ $>6 \mathrm{kPa}$ breathing room air. When controlled oxygen therapy is not able to correct hypoxia without worsening hypercapnia and acidaemia, or in those patients presenting with acidaemia, there is a large body of evidence to demonstrate that NIV is an effective therapy. ${ }^{61-64}$ NIV refers to the provision of ventilatory support via a nasal or full face mask without the use of an endotracheal tube. Studies have shown that NIV does not necessarily improve V/Q matching and the likely mechanism is also through off-loading fatigued respiratory musculature. ${ }^{54}$ Recent reviews, randomised trials, and meta-analysis have demonstrated a reduction in mortality, the need for intubation, improvements in acidaemia, shorter hospital stay, and reduced complications than standard care. ${ }^{61-65}$ It is therefore also cost effective. ${ }^{66}{ }^{67}$ NIV is the treatment of choice for acute hypercapnic respiratory failure which persists after optimal care. In addition, in contrast to invasive ventilation via an endotracheal tube, NIV can be used earlier, intermittently, and it permits physiotherapy, communication, and nutrition to continue normally. It is usually administered as pressure cycled bi-level positive airway pressure (BiPAP) indicating that the inspiratory and expiratory pressures may be independently varied. Volume cycled ventilators may also be used. An appropriate flow rate of supplemental oxygen should be added to the ventilator tubing where hypoxaemia persists. NIV is not, however, an alternative to invasive ventilation when this is clinically indicated. Based on published reviews, the relative indications and contraindications of NIV at exacerbation of COPD are listed in table 1 . Successful NIV requires trained staff but can be effectively administered on a general medical ward. ${ }^{67}$ Between $80 \%$ and $85 \%$ of patients in whom NIV is indicated may be treated successfully. It is important to have a prior treatment plan for those who fail or do not tolerate NIV: either progression to tracheal intubation or palliation with appropriate supportive care.

\section{Invasive ventilation}

The decision to institute invasive ventilation at an exacerbation of COPD is not easy and should follow a consideration of the degree of reversibility, any comorbidites, and the prior functional status and wishes of the patient, in discussion with their carers. The main indications are acidaemia and severe or worsening hypoxia. The aim is to support ventilation while disease modifying therapies act to reverse the cause of deterioration. While intubated, bronchodilator drugs may be added to the ventilator circuit using a nebuliser or via inhaler and spacer. Steroids and antibiotics are usually administered parenterally. A full discussion of invasive ventilation in the treatment of COPD is outside the scope of this review. Mortality in the intensive care unit is approximately $20 \%,{ }^{68}$ which is less than that seen in respiratory failure due to other causes. Previous therapeutic nihilism surrounding COPD is therefore unfounded. The ventilatory problem in COPD is primarily a mismatch between the respiratory load and the ability of the muscles to cope with that load, rather than being of gas exchange. ${ }^{69}$ Weaning from the ventilator can therefore be a challenging problem and NIV may have an important role in reducing weaning time, intensive care unit stay, the incidence of nosocomial pneumonia, and mortality. ${ }^{70}$

\section{Miscellaneous}

A number of strategies have been suggested to aid expectoration of secretions at exacerbation of COPD. There is no evidence supporting a benefit from respiratory physiotherapy, indeed this may be harmful, and no data are available to recommend the use of saline nebulisation. Cough and expectoration have an important role in clearing secretions and therefore antitussives are contraindicated.

A Cochrane review considering the use of helium-oxygen mixture (heliox) found no evidence of benefit. ${ }^{71}$

Other supportive care should be instituted which will include optimisation of fluid balance (diuretic therapy may be required where there is evidence of cardiac impairment), consideration of anticoagulation prophylaxis against venous thromboembolism (especially if polycythaemic), and perhaps nutritional supplementation for those with low body mass index. Although malnourished patients have a poorer outcome, there is no convincing evidence that this is reversed by nutritional supplementation.

Finally, for patients not responding to maximal therapy or in whom escalation of therapy is considered inappropriate, a range of palliative therapies may be instituted which may include the use of opiate drugs to relieve pre-terminal dyspnoea and distress. The ethical considerations in making such decisions are complex.

\section{DISCHARGE}

After an exacerbation of COPD and before hospital discharge a patient should have stable symptoms and blood gases, and be taking their home medication satisfactorily. Therapy should be optimised as described in the following section to reduce the potential for future exacerbation. Factors affecting readmission were investigated in the EFRAM study and found to include previous frequent admission, more severe underlying disease, and under-prescription of long term oxygen therapy where this is indicated. ${ }^{72}$ A follow up appointment at between four and six weeks should therefore be arranged, with repeat blood gas analysis for those having experienced respiratory failure, to guide the need for prescription of long term oxygen therapy. A number of studies, including a recent meta-analysis, have looked at early supported discharge or "hospital at home" after hospital assessment. ${ }^{73}$ Only around $25 \%$ of patients are suitable and while there is no change in mortality or readmission, duration of inpatient stay is reduced. Such schemes are not necessarily more cost effective. ${ }^{74}$

\section{PREVENTION}

Given the considerable impact that exacerbations of COPD have on both the patient and health services there is much interest in strategies designed to reduce exacerbation

\section{Key points (1)}

- An exacerbation of COPD is defined as a sustained worsening of the patient's symptoms that is acute in onset and beyond the usual day to day variation.

- Exacerbations punctuate the course of COPD and become both more frequent and more severe as the severity of the underlying COPD increases.

- Exacerbations of COPD are a considerable cause of morbidity, mortality, and health care cost.

- Most exacerbations are caused by tracheobronchial infection or pollutants. Respiratory viruses, and especially rhinovirus, are particularly important.

- Assessment of a patient who may be experiencing an exacerbation is directed to excluding differential diagnoses and evaluating the severity of the episode. 
frequency and severity. In this section we review the options available and outline the supporting evidence.

One important approach in the reduction of exacerbation morbidity is the judicious use of inhaled corticosteroids. While many large studies of inhaled steroids in stable COPD have been published, exacerbation frequency was a primary end point in only one of these. ${ }^{75}$ This study did not find a reduction in exacerbation frequency in the steroid treated patients but did note a decrease in exacerbation severity in those patients randomised to fluticasone. Evidence for the benefit of inhaled steroids on exacerbation frequency is therefore primarily from large studies such as the ISOLDE trial. $^{76}$ Here, a beneficial effect was observed in subjects taking fluticasone $1000 \mu \mathrm{g}$ per day. These patients had moderately severe underlying disease, as manifest by forced expiratory volume in one second $<50 \%$, and studies in patients with more mild disease have not shown benefit. ${ }^{77}$ Elsewhere, it has been reported that withdrawal of inhaled steroid therapy is associated with an increased risk of exacerbation. ${ }^{78}$ A meta-analysis of nine trials does suggest a relative risk reduction for a decrease in exacerbation frequency in patients treated with inhaled steroids. ${ }^{79}$ The prescription of long term, high dose inhaled corticosteroids must be balanced against the known side effects which, while less common than with oral administration, may still be a significant problem. While it has not been shown that the use of inhaled corticosteroids increases fracture rate, there is evidence of effects on surrogate markers of bone metabolism. ${ }^{80}$ Similarly, there is evidence for an increased risk of cataract, skin bruising, and oral candidiasis. Oral corticosteroids do not reduce exacerbation frequency and one study has suggested that in the minority of patients taking these drugs long term the therapy may be withdrawn without an increase in exacerbations. ${ }^{81}$

In addition to inhaled corticosteroids, there is evidence that the long acting bronchodilator agents, both $\beta_{2}$-agonists and anticholinergics, may reduce exacerbation frequency. ${ }^{82}{ }^{83}$ The $\beta_{2}$-agonists are thought to have additional anti-inflammatory properties and there may be a synergistic action in which the $\beta_{2}$-agonist assists the intranuclear localisation of the glucocorticoid receptor. Clinical trials, however, tend to demonstrate an additive rather than multiplicative effect.

A Cochrane meta-analysis has reported a benefit for influenza vaccination in the reduction of exacerbation

\section{Key points (2)}

- The mainstay of exacerbation therapy comprises inhaled bronchodilators, oral corticosteroids and, for exacerbations with increased sputum volume or purulence, oral antibiotics.

- Patients in ventilatory failure may require supportive care with oxygen, non-invasive or invasive ventilation while the therapies outlined above are able to act.

- Non-invasive ventilation is the treatment of choice for acute hypercapnic respiratory failure and reduces many of the complications associated with tracheal intubation.

- Strategies should be instituted to reduce exacerbation frequency in those with frequent exacerbations and or severe underlying disease.

- Influenza vaccination, inhaled bronchodilators, and inhaled corticosteroids reduce exacerbation frequency in appropriately selected patients.

\section{Key references}

- Siafakas NM, Anthonisen NR, Georgopoulos D, eds. Lung biology in health and disease. Volume 183: Acute exacerbations of chronic obstructive pulmonary disease. New York: Marcel Dekker, 2003.

- Pauwels R, Anthonisen N, Bailey WC, et al. Global initiative for chronic obstructive lung disease. National Heart, Lung and Blood Institute, National Institutes of Health, 2001.

- Cochrane Library (available at http://www.cochrane. org/index0.htm).

frequency in COPD. ${ }^{84}$ The data to support use of pneumococcal vaccine are less conclusive, ${ }^{8586}$ though this is still recommended in the GOLD guidelines. ${ }^{1}$

A meta-analysis considering prophylactic antibiotics in COPD or chronic bronchitis showed a small benefit in reducing exacerbations which must be weighed against the increased incidence of adverse events and concerns over antimicrobial resistance. ${ }^{87}$ Interestingly, the original studies were performed in the 1960s and there is current interest in targeting antibiotic therapy to those patients with lower airway bacterial colonisation. A recent meta-analysis of mucolytics, a class of drug rarely used in the UK, suggests a $29 \%$ reduction in exacerbations but the individual studies were of short duration and in patients with mild disease. ${ }^{88}$ Most of the benefit seen was with $\mathrm{N}$-acetyl cysteine, which also has antioxidant properties, and further trials of this drug are currently underway. One study reported a reduction in exacerbation frequency using the immunostimulatory agent OM-85 BV, an agent based on lyophilised fractions of common respiratory pathogens, but these results have not been replicated and the preparation is not in routine use. ${ }^{89}$

As described above, under-prescription of long term oxygen therapy is a risk factor for readmission to hospital and appropriate use of this therapy may therefore reduce the burden of exacerbations. Pulmonary rehabilitation has also been shown to reduce hospital admission in patients with COPD. ${ }^{90}{ }^{91}$ For patients with chronic hypercapnic respiratory failure, domiciliary NIV reduces hospitalisation, ${ }^{92-94}$ though a specific effect on exacerbation frequency has not been demonstrated. A recent study has reported a benefit for domiciliary NIV in reducing admissions in patients experiencing recurrent hypercapnic exacerbations and, furthermore, that this therapy may be cost effective. ${ }^{95}$

\section{SUMMARY}

Exacerbations of COPD impose a considerable burden on both the patient and health care system. Most exacerbations are caused by tracheobronchial infection. The diagnosis is clinical and characterised by a deterioration in the patient's symptoms. Clinical evaluation and investigation is directed to assess the severity of the episode and exclude differential diagnoses. The mainstay of treatment is with inhaled bronchodilators and oral corticosteroids. Antibiotics are indicated where there is sputum purulence. Controlled oxygen therapy is indicated in respiratory failure and, where there is acidaemia, the use of NIV or invasive ventilation should be considered. Strategies should be employed to reduce further episodes of exacerbation. These include annual influenza vaccination, the prescription of long acting bronchodilators and, for those with more severe underlying disease, inhaled corticosteroids. 


\section{QUESTIONS (TRUE (T)/FALSE (F); ANSWERS AT END OF REFERENCES)}

1. Regarding exacerbations of COPD:

(A) They account for $10 \%$ of acute medical admissions in the UK

(B) A definition including a component of health care utilisation is likely to yield a lower incidence of exacerbations than one based on change in symptoms alone

(C) Lung function tests such as forced expiratory volume in one second provide a practical guide to severity

(D) Viral exacerbations tend to be the most severe

(E) Bacterial exacerbations are more common in patients with milder underlying disease

2. The following micro-organisms are commonly associated with acute exacerbations of COPD:
(A) Haemophilus influenzae
(B) Escherichia coli
(C) Legionella pneuomphilia
(D) Human rhinovirus
(E) Streptococcus pneumoniae

3. Regarding the case history presented at the beginning of this review:

(A) Prednisolone should be prescribed at $60 \mathrm{mg}$ per day and continued for 10 days

(B) Initial oxygen therapy at $4 \mathrm{l} / \mathrm{min}$ was appropriate and should continue

(C) Salbutamol is the bronchodilator of choice at the time of acute exacerbation

(D) The hypercapnia indicates that the patient should receive doxapram

(E) Antibiotic prescription is inappropriate because there has been no increase in sputum volume or purulence

4. Regarding NIV at exacerbation of COPD:

(A) It is a useful substitute for endotracheal intubation and invasive ventilation

(B) It is superior to doxapram in the management of acute hypercapnic respiratory failure

(C) It is usually administered as continuous positive airway pressure (CPAP)

(D) It has a useful role in weaning patients from invasive ventilation

(E) It is less likely to be successful in patients with $\mathrm{pH}<7.25$ and these patients should be considered for immediate invasive ventilation

5. The following therapeutic modalities have been shown to reduce exacerbation frequency in patients with COPD:

(A) Antibiotic prophylaxis

(B) Inhaled long acting bronchodilator agents

(C) Oral corticosteroids

(D) Inhaled corticosteroids

(E) Pneumococcal vaccination

\section{Authors' affiliations}

J R Hurst, J A Wedzicha, Academic Unit of Respiratory Medicine, St Bartholomew's Hospital, London, UK

\section{REFERENCES}

1 Pauwels R, Anthonisen N, Bailey WC, et al. Global initiative for chronic obstructive lung disease. National Heart, Lung and Blood Institute, National Institutes of Health, 2001.

2 Donaldson GC, Seemungal TAR, Patel IS, et al. Longitudinal changes in the nature, severity and frequency of COPD exacerbations. Eur Respir $J$ 2003;22:931-6.

3 Vestbo J, Rasmussen FV. Respiratory symptoms and FEV 1 as predictors of hospitalization and medication in the following 12 years due to respiratory disease. Eur Respir J 1989:2:710-15.

4 Seemungal TAR, Donaldson GC, Paul EA, et al. Effect of exacerbation on quality of life in patients with chronic obstructive pulmonary disease. Am J Respir Crit Care Med 1998;157:1418-22.

5 Rodriguez-Roisin R. Toward a consensus definition for COPD exacerbations. Chest 2000;117(suppl):398S-408S

6 Seemungal T, Harper-Owen R, Bhowmik A, et al. Respiratory viruses, symptoms, and inflammatory markers in acute exacerbations and stable chronic obstructive pulmonary disease. Am J Respir Crit Care Med 2001; 164:1618-23.

7 Greenberg SB, Allen M, Wilson J, et al. Respiratory viral infections in adults with and without chronic obstructive pulmonary disease. Am J Respir Crit Care Med 2000;162:167-73.

8 Donaldson GC, Seemungal T, Jeffries DJ, et al. Effect of temperature on lung function and symptoms in chronic obstructive pulmonary disease. Eur Respir J 1999; 13:844-9.

9 Seemungal TAR, Harper-Owen R, Bhowmik A, et al. Detection of rhinovirus in induced sputum at exacerbation of chronic obstructive pulmonary disease. Eur Respir J 2000;16:677-83.

10 Zalacain R, Sobradillo V, Amilibia J, et al. Predisposing factors to bacterial colonization in chronic obstructive pulmonary disease. Eur Respir $J$ 1999;13:343-8.

11 Patel IS, Seemungal TAR, Wilks $M$, et al. Relationship between bacterial colonisation and the frequency, character and severity of COPD exacerbations. Thorax 2002;57:759-64.

12 Wilkinson TMA, Patel IS, Wilks $M$, et al. Airway bacterial load and FEV decline in patients with chronic obstructive pulmonary disease. Am J Respir Crit Care Med 2003; 167:1090-5.

13 Sethi S, Evans N, Grant BJB, et al. New strains of bacteria and exacerbations of chronic obstructive pulmonary disease. N Engl J Med 2002;347:465-71.

14 Stockley RA, O'Brien C, Pye A, et al. Relationship of sputum color to nature and outpatient management of acute exacerbations of COPD. Chest 2000; 117:1638-45.

15 Anderson HR, Spix C, Medina S, et al. Air pollution and daily admissions for chronic obstructive pulmonary disease in 6 European cities: results from the APHEA project. Eur Respir J 1997;10:1064-71.

16 Lung and Asthma Information Agency. Trends in emergency hospital admissions for lung disease. Fact sheet 2001/4. London: St George's Hospital Medical School.

17 Ashton CM, Ferguson JA, Goldacre MJ. In-patient workload in medical specialities - 2. Profiles of individual diagnoses from linked statistics. Q J Med 1995;88:661-72.

18 Connors AF Jr, Dawson NV, Thomas C, et al. Outcomes following acute exacerbation of severe chronic obstructive lung disease. Am J Respir Crit Care Med 1996; 154:959-67

19 Kanner RE, Anthonisen NR, Connett JE, for the Lung Health Study Research Group. Lower respiratory illnesses promote $\mathrm{FEV}_{1}$ decline in current smokers but not ex-smokers with mild chronic obstructive pulmonary disease. Results from the Lung Health Study. Am J Respir Crit Care Med 2001;164:358-64.

20 Donaldson GC, Seemungal TAR, Bhowmik A, et al. Relationship between exacerbation frequency and lung function decline in chronic obstructive pulmonary disease. Thorax 2002;57:847-52.

21 Sullivan SD, Ramsey SD, Lee TA. The economic burden of COPD. Chest 2000;117(suppl):5S-9S.

22 American Thoracic Society. Standards for the diagnosis of patients with chronic obstructive pulmonary disease (COPD) and asthma. Am Rev Respir Dis 1987; 136:225-44.

23 O'Donnell DE, Aaron S, Bourbeau J, et al. Canadian Thoracic Society recommendations for management of chronic obstructive pulmonary disease-2003. Can Respir J 2003;10(suppl A):11A-65A

24 European Respiratory Society Task Force. Optimal assessment and management of chronic obstructive pulmonary disease. Eur Respir J 1995;8:1398-420.

25 COPD Guidelines Group of the Standards of Care Committee of the BTS. BTS guidelines for the management of chronic obstructive pulmonary disease. Thorax 1997;52(suppl 5):S1-S28.

26 National Institute for Clinical Excellence. Chronic obstructive pulmonary disease (COPD): management of chronic obstructive pulmonary disease in primary and secondary care. Thorax 2004;59(suppl):i1-i232.

27 Warren PM, Flenley DC, Millar JS, et al. Respiratory failure revisited: acute exacerbations of chronic bronchitis between 1961-68 and 1970-76. Lancet 1980;i:467-70

28 Belman MJ, Botnick WC, Shin JW. Inhaled bronchodilators reduce dynamic hyperinflation during exercise in patients with chronic obstructive pulmonary disease. Am J Respir Crit Care Med 1996;153:967-75.

29 Braun SR, McKenzie WN, Copeland C, et al. A comparison of the effect of ipratropium and albuterol in the treatment of chronic obstructive airway disease. Arch Intern Med 1989;149:544-7.

30 McCrory DC, Brown CD. Anticholinergic bronchodilators versus beta2sympathomimetic agents for acute exacerbations of chronic obstructive 
pulmonary disease (Cochrane methodology review). The Cochrane Library, Issue 4, 2003. Chichester, UK: John Wiley \& Sons.

31 Turner MO, Patel A, Ginsburg S, et al. Bronchodilator delivery in acute airflow obstruction. A meta-analysis. Arch Intern Med 1997:157:1736-44.

32 Turner MO, Gafni A, Swan D, et al. A review and economic evaluation of bronchodilator delivery methods in hospitalized patients. Arch Intern Med 1996; 156:2113-18

33 Levitt MA, Gambrioli EF, Fink JB. Comparative trial of continuous nebulization versus metered-dose inhaler in the treatment of acute bronchospasm. Ann Emerg Med 1995;26:273-7.

34 Saetta M, Di Stefano A, Maestrelli P, et al. Airway eosinophilia in chronic bronchitis during exacerbations. Am J Respir Crit Care Med 1994; 150:1646-52

35 Bhowmik A, Seemungal TAR, Sapsford RJ, et al. Relation of sputum inflammatory markers to symptoms and lung function changes in COPD exacerbations. Thorax 2000;55:114-20.

36 Singh JM, Palda VA, Stanbrook MB, et al. Corticosteroid therapy for patients with acute exacerbations of chronic obstructive pulmonary disease. A systematic review. Arch Intern Med 2002;162:2527-36.

37 Wood-Baker R, Walters EH, Gibson P. Oral corticosteroids for acute exacerbations of chronic obstructive pulmonary disease (Cochrane methodology review). The Cochrane Library, Issue 4, 2003. Chichester, UK: John Wiley \& Sons.

38 Murata GH, Gorby MS, Chick TW, et al. Intravenous and oral corticosteroids for the prevention of relapse after treatment of decompensated COPD. Effect on patients with a history of multiple relapses. Chest 1990;98:845-9.

39 Seemungal TAR, Donaldson GC, Bhowmik A, et al. Time course and recovery of exacerbations in patients with chronic obstructive pulmonary disease. Am J Respir Crit Care Med 2000;161:1608-13.

40 O'Driscoll BR, Kalra S, Wilson M, et al. Double-blind trial of steroid tapering in acute asthma. Lancet 1993:341:324-7.

41 Niewoehner DE, Erbland ML, Deupree RH, et al. Effect of systemic glucocorticoids on exacerbations of chronic obstructive pulmonary disease. N Engl J Med 1999;340:1941-7.

42 Albert RK, Martin TR, Lewis SW. Controlled clinical trial of methylprednisolone in patients with chronic bronchitis and acute respiratory insufficiency. Ann Intern Med 1980;92:753-8.

43 Maltais F, Ostinelli J, Bourbeau J, et al. Comparison of nebulized budesonide and oral prednisolone with placebo in the treatment of acute exacerbations of chronic obstructive pulmonary disease. A randomized controlled trial. Am J Respir Crit Care Med 2002;165:698-703.

44 Anthonisen NR, Manfreda J, Warren CP, et al. Antibiotic therapy in exacerbations of chronic obstructive pulmonary disease. Ann Intern Med 1987; 106:196-204

45 Sachs APE, Koeter GH, Groenier KH, et al. Changes in symptoms, peak expiratory flow, and sputum flora during treatment with antibiotics of exacerbations in patients with chronic obstructive pulmonary disease in general practice. Thorax 1995:50:758-63.

46 Saint S, Bent S, Vittinghoff E, et al. Antibiotics in chronic obstructive pulmonary disease exacerbations. A meta-analysis. JAMA 1995;273:957-60.

47 Adam S, Melo J, Anuzueto A. Effects of antibiotics on the recurrence rates of chronic obstructive pulmonary disease exacerbations. Chest 1997;112(suppl):22S

48 Destache CJ, Dewan N, O'Donohue WJ, et al. Clinical and economic considerations in the treatment of acute exacerbations of chronic bronchitis. $J$ Antimicrob Chemother 1999:43(suppl A): 107-13.

49 Powell M, McVey D, Kassim MH, et al. Antimicrobial susceptibility of Streptococcus pneumoniae, Haemophilus influenzae and Moraxella (Branhamellea) catarrhalis isolated in the UK from sputa. I Antimicrob Chemother 1991:28:249-59.

$50 \mathrm{Sin}$ DD, Tu JV. Outpatient antibiotic therapy and short term mortality in elderly patients with chronic obstructive pulmonary disease. Can Respir J 2000;7:466-71.

51 Barr RG, Rowe BH, Camargo CA Jr. Methylxanthines for exacerbations of chronic obstructive pulmonary disease: meta-analysis of randomised trials. BMJ 2003;327:643-6.

52 Angus RM, Ahmed AA, Fenwick $\sqcup$, et al. Comparison of the acute effects on gas exchange of nasal ventilation and doxapram in exacerbations of chronic obstructive pulmonary disease. Thorax 1996;51:1048-50.

53 Greenstone M, Lasserson TJ. Doxapram for ventilatory failure due to exacerbations of chronic obstructive pulmonary disease (Cochrane methodology review). The Cochrane Library, Issue 4, 2003. Chichester, UK: John Wiley \& Sons.

54 Barbera JA, Roca J, Ferrer A, et al. Mechanisms of worsening gas exchange during acute exacerbations of chronic obstructive pulmonary disease. Eur Respir J 1997; 10:1285-91.

55 Plant PK, Owen J, Elliot MW. One year period prevalence study of respiratory acidosis in acute exacerbation of COPD: implications for the provision of noninvasive ventilation and oxygen administration. Thorax 2000;55:550-4.

56 Robinson TD, Freiberg DB, Regnis JA, et al. The role of hypoventilation and ventilation-perfusion redistribution in oxygen-induced hypercapnia during acute exacerbations of chronic obstructive pulmonary disease. Am J Respir Crit Care Med 2000;161:1524-9.

57 Moloney ED, Kiely JL, MCNicholas WT. Controlled oxygen therapy and carbon dioxide retention during exacerbations of chronic obstructive pulmonary disease. Lancet 2001;357:526-8.

58 Costello RW, Liston R, McNicholas WT. Compliance at night with low flow oxygen therapy: a comparison of nasal cannulae and Venturi face masks. Thorax 1995;50:405-6.
59 Agusti AGN, Carrera M, Barbe F, et al. Oxygen therapy during exacerbations of chronic obstructive pulmonary disease. Eur Respir $J$ 1999; 14:934-9.

60 Fajac I, Texereau J, Rivoal V, et al. Blood gas measurement during exercise: a comparative study between arterialized earlobe sampling and direct arterial puncture in adults. Eur Respir J 1998;11:712-5.

61 Bott J, Carroll MP, Conway JH, et al. Randomised controlled trial of nasal ventilation in acute ventilatory failure due to chronic obstructive airways disease. Lancet 1993:341:1555-7.

62 Brochard L, Mancebo J, Wysocki M, et al. Noninvasive ventilation for acute exacerbations of chronic obstructive pulmonary disease. N Engl I Med 1995;333:817-22.

63 Kramer N, Meyer TJ, Meharg J, et al. Randomized, prospective trial of noninvasive positive pressure ventilation in acute respiratory failure. Am J Respir Crit Care Med 1995;151:1799-806.

64 Plant PK, Owen JL, Elliott MW. Early use of non-invasive ventilation for acute exacerbations of chronic obstructive pulmonary disease on general respiratory wards: a multicentre randomised controlled trial. Lancet 2000;355:1931-5

65 Lightowler JV, Wedzicha JA, Elliott MW, et al. Non-invasive positive pressure ventilation to treat respiratory failure resulting from exacerbations of chronic obstructive pulmonary disease: Cochrane systematic review and metaanalysis. BMJ 2003;326:185-7.

66 Keenan SP, Gregor J, Sibbald WJ, et al. Noninvasive positive pressure ventilation in the setting of severe, acute exacerbations of chronic obstructive pulmonary disease: more effective and less expensive. Crit Care Med 2000;28:2094-102.

67 Plant PK, Owen JL, Parrott S, et al. Cost effectiveness of ward based noninvasive ventilation for acute exacerbations of chronic obstructive pulmonary disease: economic analysis of randomised controlled trial. BMJ 2003;326:956-9.

68 Esteban A, Anzueto A, Frutos F, et al. Characteristics and outcomes in adult patients receiving mechanical ventilation. A 28-day international study. JAMA 2002; $287: 345-55$

69 Purro A, Appendini L, De Gaetano A, et al. Physiologic determinants of ventilator dependence in long-term mechanically ventilated patients. Am J Respir Crit Care Med 2000;161:1115-23.

70 Nava S, Ambrosino N, Clini E, et al. Noninvasive mechanical ventilation in the weaning of patients with respiratory failure due to chronic obstructive pulmonary disease. A randomized, controlled trial. Ann Intern Med 1998;128:721-8

71 Rodrigo G, Pollack C, Rodrigo C, et al. Heliox for treatment of exacerbations of chronic obstructive pulmonary disease (Cochrane review). The Cochrane Library, Issue 4, 2003. Chichester, UK: John Wiley \& Sons.

72 Garcia-Aymerich J, Monso E, Marrades RM, et al. Risk factors for hospitalization for a chronic obstructive pulmonary disease exacerbation. EFRAM Study. Am J Respir Crit Care Med 2001:164:1002-7.

73 Ram FSF, Wedzicha JA, Wright J, et al. Hospital at home for acute exacerbations of chronic obstructive pulmonary disease (Cochrane review). The Cochrane Library, Issue 4, 2003. Chichester, UK: John Wiley \& Sons.

74 Shepperd S, Harwood D, Jenkinson C, et al. Randomised controlled trial comparing hospital at home care with inpatient hospital care. I: three month follow up of health outcomes. BMJ 1998;316:1786-91

75 Paggiaro PL, Dahle R, Bakran I, et al. Multicentre randomised placebocontrolled trial of inhaled fluticasone propionate in patients with chronic obstructive pulmonary disease. Lancet 1998;351:773-80.

76 Burge PS, Calverley PM, Jones PW, et al. Randomised, double blind, placebo controlled study of fluticasone propionate in patients with moderate to severe chronic obstructive pulmonary disease: the ISOLDE trial. BMJ 2000;320: 1297-303

77 Vestbo J, Sorensen T, Lange P, et al. Long-term effect of inhaled budesonide in mild and moderate chronic obstructive pulmonary disease: a randomised controlled trial. Lancet 1999:353:1819-23.

78 Jarad NA, Wedzicha JA, Burge PS, et al. An observational study of inhaled corticosteroid withdrawal in stable chronic obstructive pulmonary disease. Respir Med 1999:93:161-6.

79 Alsaeedi A, Sin DS, McAlister FA. The effects of inhaled corticosteroids in chronic obstructive pulmonary disease: a systematic review of randomized placebo-controlled trials. Am J Med 2002;1 13:59-65.

80 Lipworth BJ. Systemic adverse effects of inhaled corticosteroid therapy. A systematic review and meta-analysis. Arch Intern Med 1999;159:941-55.

81 Rice KL, Rubins JB, Lebahn F, et al. Withdrawal of chronic systemic corticosteroids in patients with COPD. A randomized trial. Am J Respir Crit Care Med 2000;162:174-8

82 Mahler DA, Donohue JF, Barbee RA, et al. Efficacy of salmeterol xinafoate in the treatment of COPD. Chest 1999;115:957-65.

83 Vincken W, van Noord JA, Greefhorst AP, et al. Improved health outcomes in patients with COPD during 1 years treatment with tiotropium. Eur Respir $J$ 2002;19:209-16.

84 Poole PJ, Chacko E, Wood-Baker RWB, et al. Influenza vaccine for patients with chronic obstructive pulmonary disease (Cochrane review). The Cochrane Library, Issue 4, 2003. Chichester, UK: John Wiley \& Sons.

85 Williams JH Jr, Moser KM. Pneumococcal vaccine and patients with chronic lung disease. Ann Intern Med 1986;104:106-9.

86 Davis AL, Aranda CP, Schiffman G, et al. Pneumococcal infection and immunologic response to pneumococcal vaccine in chronic obstructive pulmonary disease. A pilot study. Chest 1987;92:204-12.

87 Staykova T, Black P, Chacko E, et al. Prophylactic antibiotic therapy for chronic bronchitis (Cochrane review). The Cochrane Library, Issue 4, 2003. Chichester, UK: John Wiley \& Sons. 
88 Poole PJ, Black PN. Mucolytic agents for chronic bronchitis or chronic obstructive pulmonary disease (Cochrane review). The Cochrane Library, Issue 4, 2003. Chichester, UK: John Wiley \& Sons.

89 Collet JP, Shapiro S, Ernst $P$, et al. Effects of an immunostimulating agent on acute exacerbations and hospitalizations in patients with chronic obstructive pulmonary disease. Am J Respir Crit Care Med 1997; 156:1719-24.

90 Foglio K, Bianchi L, Bruletti G, et al. Long-term effectiveness of pulmonary rehabilitation in patients with chronic airway obstruction. Eur Respir J 1999;13:125-32.

91 Guell R, Casan P, Belda J, et al. Long-term effects of outpatient rehabilitation of COPD. A randomised trial. Chest 2000;117:976-83.

92 Leger $\mathbf{P}$, Bedicam JM, Cornette A, et al. Nasal intermittent positive pressure ventilation. long-term follow-up in patients with severe chronic respiratory insufficiency. Chest 1994; 105:100-5.
93 Jones SE, Packham S, Hebden M, et al. Domiciliary nocturnal intermittent positive pressure ventilation in patients with respiratory failure due to severe COPD: long term follow up and effect on survival. Thorax 1998;53:495-8.

94 Perrin C, El Far Y, Vandenbos F, et al. Domiciliary nasal intermittent positive pressure ventilation in severe COPD: effects on lung function and quality of ife. Eur Respir J 1997; 10:2835-9.

95 Tuggey JM, Plant PK, Elliott MW. Domiciliary non-invasive ventilation for recurrent acidotic exacerbations of COPD: an economic analysis. Thorax 2003;58:867-71

\section{ANSWERS}

1. (A) T, (B) T, (C) F, (D) T, (E) F; 2. (A) T, (B) F, (C) F, (D)

T, (E) T; 3. (A) F, (B) F, (C) T, (D) F, (E) T; 4. (A) F, (B) T, (C)

$\mathrm{F}$, (D) T, (E) T; 5. (A) T, (B) T, (C) F, (D) T, (E) F.

\section{Clinical Evidence - Call for contributors}

Clinical Evidence is a regularly updated evidence based journal available worldwide both as a paper version and on the internet. Clinical Evidence needs to recruit a number of new contributors. Contributors are health care professionals or epidemiologists with experience in evidence based medicine and the ability to write in a concise and structured way.

\section{Currently, we are interested in finding contributors with an interest in} the following clinical areas:

Altitude sickness; Autism; Basal cell carcinoma; Breast feeding; Carbon monoxide poisoning; Cervical cancer; Cystic fibrosis; Ectopic pregnancy; Grief/bereavement; Halitosis; Hodgkins disease; Infectious mononucleosis (glandular fever); Kidney stones; Malignant melanoma (metastatic); Mesothelioma; Myeloma; Ovarian cyst; Pancreatitis (acute); Pancreatitis (chronic); Polymyalgia rheumatica; Post-partum haemorrhage; Pulmonary embolism; Recurrent miscarriage; Repetitive strain injury; Scoliosis; Seasonal affective disorder; Squint; Systemic lupus erythematosus; Testicular cancer; Varicocele; Viral meningitis; Vitiligo However, we are always looking for others, so do not let this list discourage you.

\section{Being a contributor involves:}

- Appraising the results of literature searches (performed by our Information Specialists) to identify high quality evidence for inclusion in the journal.

- Writing to a highly structured template (about 2000-3000 words), using evidence from selected studies, within 6-8 weeks of receiving the literature search results.

- Working with Clinical Evidence Editors to ensure that the text meets rigorous epidemiological and style standards.

- Updating the text every eight months to incorporate new evidence.

- Expanding the topic to include new questions once every 12-18 months.

If you would like to become a contributor for Clinical Evidence or require more information about what this involves please send your contact details and a copy of your CV, clearly stating the clinical area you are interested in, to Claire Folkes (cfolkes@bmigroup.com).

\section{Call for peer reviewers}

Clinical Evidence also needs to recruit a number of new peer reviewers specifically with an interest in the clinical areas stated above, and also others related to general practice. Peer reviewers are health care professionals or epidemiologists with experience in evidence based medicine. As a peer reviewer you would be asked for your views on the clinical relevance, validity, and accessibility of specific topics within the journal, and their usefulness to the intended audience (international generalists and health care professionals, possibly with limited statistical knowledge). Topics are usually 2000-3000 words in length and we would ask you to review between 2-5 topics per year. The peer review process takes place throughout the year, and our turnaround time for each review is ideally 10-14 days.

If you are interested in becoming a peer reviewer for Clinical Evidence, please complete the peer review questionnaire at www.clinicalevidence.com or contact Claire Folkes(cfolkes@bmigroup.com). 